\title{
PENGARUH PEMANFAATAN TEKNOLOGI INFORMASI TERHADAP KINERJA GURU PADA SMP NEGERI 43 BANDUNG
}

\author{
Asye Rachmawaty, S.T., M.M. \\ Dosen Program Studi Manajemen Informatika \\ Politeknik LP3I Bandung \\ E-Mail : asyerachmawaty@gmail.com
}

\begin{abstract}
Abstrak : Tujuan Penelitian ini adalah ingin mengetahui dan menganalisa pemanfaatan teknologi informasi dan kinerja guru serta pengaruh pemanfaatan teknologi informasi terhadap kinerja guru Sekolah Menengah Pertama Negeri 43 Bandung, baik secara simultan maupun secara parsial.
\end{abstract}

Metode penelitian yang digunakan adalah deskriptif dan verifikatif. Unit analisis dalam penelitian ini adalah seluruh guru Pegawai Negeri Sipil pada Sekolah Menengah Pertama Negeri 43 Bandung dengan populasi sebanyak 38 orang. Tipe investigasinya adalah kausalitas dengan time horizon ini adalah cross-sectional.

Berdasarkan hasil penelitian dan pembahasan, maka diperoleh bahwa pemanfaatan teknologi informasi pada Sekolah Menengah Pertama Negeri 43 Bandung memiliki tingkat pemanfaatan yang baik. Pemanfaatan teknologi informasi secara simultan dan parsial mempunyai pengaruh terhadap kinerja guru.

Kata Kunci: Pemanfaatan Teknologi Informasi, Kinerja Guru

\section{Pendahuluan}

Proses pembelajaran pada satuan pendidikan diselenggarakan secara interaktif, inspiratif, menyenangkan, menantang, memotivasi peserta didik untuk berpartisipasi aktif, serta memberikan ruang yang cukup bagi prakarsa, kreativitas, dan kemandirian sesuai dengan bakat, minat, dan perkembangan fisik serta psikologis peserta didik. (Peraturan Pemerintah Nomor 19 Tahun 2005). Berdasarkan hasil riset yang dikemukakan dalam Pedoman Pemenuhan Standar Nasional Pendidikan pada SMP/MTS oleh Pusat Penjaminan Mutu Pendidikan tahun 2012 bahwa sekolah dan madrasah merupakan pihak yang memberikan kontribusi terbesar terhadap proses dan hasil penjaminan mutu dan peningkatan mutu pendidikan, sedangkan masyarakat, penyelenggara pendidikan, dan pemerintah daerah memberikan fasilitasi dalam pelaksanaan penjaminan mutu tersebut.

Banyak faktor yang berpengaruh atau mendukung terwujudnya proses pembelajaran yang berkualitas dalam upaya mencapai tujuan pendidikan, salah satu diantaranya adalah penggunaan atau pemanfaatan teknologi dalam proses pendidikan dan pembelajaran (Miarso, 2004). Teknologi pembelajaran yang dewasa ini aplikasinya berupa pemanfaatan proses dan produk teknologi informasi dan komunikasi (information and communication technology/ITC) untuk 
memecahkan masalah-masalah pendidikan dan pembelajaran, memiliki banyak manfaat atau keuntungan (Herman D. Surjono, 2010). Dengan memperhatikan keunggulan berbagai bentuk teknologi pembelajaran, dapat disusun strategi pemanfaatan yang tepat dan optimal untuk meningkatkan kualitas serta efektivitas dan efisiensi pembelajaran.

Kehadiran Teknologi Informasi dan Komunikas terutama komputer dan internet sudah lama dimanfaatkan oleh negara-negara maju. Misalnya, di negara seperti Inggris, Amerika, dan Jepang. Teknologi informasi dan komunikasi digunakan dalam kegiatan pembelajaran di sekolah-sekolah melalui pemanfaatan komputer dengan didukung teknologi internet. Dengan teknologi komputer dan internet, para siswa atau mahasiswa tidak hanya dapat belajar di dalam kelas. Mereka dapat belajar di mana pun karena hampir semua materi pelajaran dapat diiperoleh melalui CD atau langsung diakses melalui internet. (Dinkominfo, 2013).

Komponen utama lainnya yang mempengaruhi keberhasilan pendidikan adalah komponen guru. Definisi guru diatur dalam Undang-undang Nomor 14 Tahun 2005 tentang Guru dan Dosen. Guru mempunyai kedudukan sebagai tenaga profesional pada jalur pendidikan formal yang diangkat sesuai dengan peraturan perundangundangan. Pengakuan kedudukan guru sebagai tenaga professional dibuktikan dengan sertifikat pendidik. Lebih lanjut Undang-Undang Nomor 14 Tahun 2005 tentang Guru dan Dosen mendefinisikan bahwa profesional adalah pekerjaan atau kegiatan yang dilakukan oleh seseorang dan menjadi sumber penghasilan kehidupan yang memerlukan keahlian, kemahiran, atau kecakapan yang memenuhi standar mutu atau norma tertentu serta memerlukan pendidikan profesi.

Kewajiban guru sesuai dengan Peraturan Pemerintah Nomor 74 tentang Guru Pasal 52 ayat (1) yang terdapat dalam Pedoman Pelaksanaan Tugas Guru dan Pengawas, mencakup kegiatan pokok yaitu merencanakan pembelajaran, melaksanakan pembelajaran, menilai hasil pembelajaran, membimbing dan melatih peserta didik, serta melaksanakan tugas tambahan yang melekat pada pelaksanaan tugas pokok. Dalam penjelasan Pasal 52 ayat (1) huruf (e), yang dimaksud dengan "tugas tambahan", misalnya menjadi pembina pramuka, pembimbing kegiatan karya ilmiah remaja, dan guru piket.

Guru profesional tidak dilahirkan, tetapi dibentuk oleh suatu pengalaman belajar yang bermutu. Pendidikan guru harus mampu menyediakan pengalaman belajar yang bermutu. Demikian juga sekolah tempat guru bekerja selayaknya memiliki budaya mutu. Sehingga calon guru dan guru menyadari pentingnya pembelajaran seumur hidup (lifelong learning). Darling-Hammond (2006) dalam Jejen Musfah (2011:78) menegaskan, "Tim riset kami menanyai para praktisi di berbagai negeri menyimpulkan bahwa guru terbaik adalah disiapkan, guru ini memiliki pengetahuan yang mendalam tentang penilaian dan kurikulum, pemahaman mereka tentang individu siswa, dan kapasitas mereka untuk menggunakan strategi pengajaran yang canggih; untuk melibatkan para pelajar yang berbeda dengan jelas secara seketika". Messa Media Gusti dalam Jurnal (2012) menyimpulkan 
bahwa kinerja guru adalah prestasi yang dicapai sebagai hasil kerja seorang guru dalam melaksanakan tugas dan tanggung jawab yang dibebankan kepadanya sesuai kewenangan dan kemampuan yang dimiliki.

Pemanfaatan teknologi informasi merupakan sarana penunjang/pendorong bagi organisasi dalam mencapai tujuan organisasi.. Pemanfaatan teknologi informasi dapat dilakukan secara efektif jika anggota dalam organisasi dapat menggunakan teknologi tersebut dengan baik. Pemanfaatan teknologi yang efektif dapat meningkatkan kinerja. Hal ini sesuai dengan model penerimaan teknologi (technology acceptance model / TAM). Sehingga, semakin tinggi kinerja individu semakin meningkat pula efektifitas, produktivitas dan kualitas pelayanan individu tersebut.

\section{Tinjauan Tentang Teknologi Informasi}

Definisi teknologi informasi yang lain dikemukakan Nina W. Syam (2004) dalam Ali Muhtadi (2013:4). Menurutnya teknologi informasi dapat dimaknai sebagai ilmu yang diperlukan untuk memanag informasi agar informasi tersebut dapat ditelusuri kembali dengan mudah dan akurat. Isi ilmu tersebut dapat berupa prosedur dan teknik-teknik untuk menyimpan dan mengelola informasi secara efisien dan efektif. Lebih lanjut menurut Nina W. Syam, informasi dipandang sebagai data yang telah diolah dan dapat disimpan baik dalam bentuk tulisan, suara, maupun dalam bentuk gambar, dimana gambar tersebut dapat berupa gambar mati atau gambar hidup. Sedang informasi yang dikelola atau disampaikan melalui teknologi informasi tersebut dapat berupa ilmu dan pengetahuan itu sendiri. Bila informasi tersebut volumenya kecil tentu tidak memerlukan teknik-teknik atau prosedur yang rumit untuk menyimpannya. Namun bila informasi tersebut dalam volume yang cukup besar, maka diperlukan teknik atau prosedur tertentu untuk menyimpannya, agar mudah menemukan kembali informasi yang tersimpan. Teknik atau prosedur untuk mengelola informasi itulah yang disebut dengan teknologi informasi.

Menurut Suwarsih Madya (2011), untuk menjaga agar pemanfaatan TIK tetap memberikan kontribusi signifikan terhadap (1) pengembangan peserta didik menjadi manusia berkarakter dan berkecerdasan intelektual dan (2) pemberdayaan pendidik dan tenaga kependidikan terkait, hendaknya diterapkan prinsip-prinsip berikut:

1. Pemanfaatan TIK dalam pendidikan sebaiknya mempertimbangkan karaktersitik peserta didik, pendidik, dan tenaga kependidikan dalam keseluruhan pembuatan keputusan TIK.

2. Pemanfaatan TIK sebaiknya dirancang untuk memperkuat minat dan motivasi pengguna untuk menggunakannya semata guna meningkatkan dirinya, baik dari segi intelektual, spiritual (rohani), sosial, maupun ragawi.

3. Pemanfaatan TIK sebaiknya menumbuhkan kesadaran dan keyakinan akan pentingnya kegiatan berinteraksi langsung dengan manusia (tatap muka), dengan lingkungan sosial-budaya (pertemuan, museum, tempat-tempat bersejarah), dan lingkungan alam (penjelajahan) agar tetap mampu 
memelihara nilai-nilai sosial dan humaniora (seni dan budaya), dan kecintaan terhadap alam sebagai anugerah dari Tuhan Yang Maha Esa.

4. Pemanfaatan TIK sebaiknya menjaga bahwa kelompok sasaran tetap dapat mengapresiasi teknologi komunikasi yang sederhana dan kegiatan-kegiatan pembelajaran tanpa TIK karena tuntutan penguasaan kompetensi terkait dalam rangka mengembangkan seluruh potensi siswa secara seimbang.

5. Pemanfaatan TIK sebaiknya mendorong pengguna untuk menjadi lebih kreatif dan inovatif sehingga tidak hanya puas menjadi konsumen informasi berbasis TIK.

TAM (Technology Acceptance Model) menyatakan bahwa pemanfaatan teknologi informasi dapat meningkatkan kinerja. Kinerja berhubungan dengan pencapaian serangkaian tugas-tugas yang dilaksanakan oleh individu individu didalam organisasi (Thai FJ ; 2002). Adapun indikator dalam TAM (Technology Acceptance Model) menurut Davis, F. D., Bagozzi, R. P., and Warshaw, P. R. (1989) adalah sebagai berikut:

1. Attitude: Individual's positive or negative feeling about performing the target behavior (e.g., using a system).

2. Behavioral intention: The degree to which a person has formulated conscious plans to perform or not perform some specified future behavior.

3. Computer anxiety: The degree of an individual's apprehension, or even fear, when she/he is faced with the possibility of using computers.

4. Computer playfulness: The degree of cognitive spontaneity in microcomputer interactions.

5. Computer self-efficacy: The degree to which an individual beliefs that he or she has the ability to perform specific task/job using computer.

6. Effort expectancy: The degree of ease associated with the use of the system.

7. Facilitating conditions: The degree to which an individual believes that an organizational and technical infrastructure exists to support use of the system.

8. Image: The degree to which use of an innovation is perceived to enhance one's status in one's social system.

9. Job relevance: Individual's perception regarding the degree to which the target system is relevant to his or her job.

10. Objective usability: A comparison of systems based on the actual level (rather than perceptions) of effort required to complete specific tasks.

11. Output quality: The degree to which an individual believes that the system performs his or her job tasks well.

12. Performance expectancy: The degree to which an individual believes that using the system will help him or her to attain gains in job performance.

13. Perceived ease of use: See the definition of effort expectancy.

14. Perceived enjoyment: The extent to which the activity of using a specific system is perceived to be enjoyable in it's own right, aside from any performance consequences resulting from system use.

15. Perceived usefulness: See the definition of performance expectancy.

16. Perception of external control: See the definition of facilitating conditions. 
17. Result demonstrability: Tangibility of the results of using the innovation.

18. Social influence: The degree to which an individual perceives that important others believe he or she should use the new system.

19. Subjective norm: Person's perception that most people who are important to him think he should or should not perform the behavior in question.

20. Voluntariness: The extent to which potential adopters perceive the adoption decision to be non-mandatory.

\section{Tinjauan Kinerja}

Kinerja berasal dari pengertian performance. Kinerja mempunyai makna yang lebih luas, bukan hanya hasil kerja, tetapi termasuk bagaimana proses pekerjaan berlangsung. (Wibowo, 2013:7).

Kinerja menurut Wirawan (2009:5), adalah keluaran yang dihasilkan oleh fungsifungsi atau indikator-indikator suatu pekerjaan atau suatu profesi dalam waktu tertentu. Menurut Wirawan (2009:54-55) secara umum dimensi kinerja dapat dikelompokkan menjadi tiga jenis, yaitu:

1. Hasil kerja, merupakan keluaran kerja dalam bentuk barang atau jasa yang dapat dihitung dan diukur kuntitas serta kualitasnya. Pengukuran kinerja melalui hasil kerja pekerja sejalan dengan pendapat Peter Drucker melalui teori Management by Objectives (MBO). Misalnya, kuantitas hasil kerja seorang sales mobil diukur seberapa banyak pelanggan yang dilayaninya. Kualitasnya diukur seberapa tepat sales tersebut melakukan pelayanan sesuai dengan ketentuan yang ada dan seberapa puas penggan yang dilayaninya.

2. Perilaku kerja, ketika berada di tempat kerja karyawan memiliki dua perilaku yaitu perilaku pribadi dan perilaku kerja. Perilaku pribadi merupakan perilaku yang tidak berhubungan dengan pekerjaan, misalnya: cara berjalan, cara berbicara, cara menulis, dan sebagainya. Perilaku kerja adalah perilaku pekerja yang berhubungan dengan pekerjaan, misalnya: kerja keras, ramah, disiplin, kreatif, dan sebagainya. Perilaku kerja dicantumkan dalam standar kinerja, prosedur kerja, kode etik, dan peraturan organisasi yang dapat dikelompokkan menjadi perilaku kerja umum dan khusus. Perilaku kerja umum merupakan perilaku kerja yang diperlukan semua jenis pekerjaan, misalnya: loyal dalam organisasi, disiplin, dan bekerja keras. Perilaku kerja khusus diperlukan untuk pekerjaan tertentu, misalnya: satpam dituntut tegas dan tidak banyak bicara, penjual dituntut ramah dan ceria dalam melayani pelanggan.

3. Sifat pribadi yang berhubungan dengan pekerjaan, sifat yang dinilai seperti: penampilan, sikap terhadap pekerjaan, jujur, cerdas, dan sebagainya. Misalnya, seorang pramusaji sebuah rumah makan dituntut mempunyai sifat pribadi bersih, wangi, ramah, santun, pandai bergaul, dan periang. Evaluasi menggunakan sifat pribadi mudah dan universal, karena hanya menentukan indikator sifat pribadi dan deskripsi level kinerja dalam bentuk kata sifat dan angka. 


\section{Kinerja Guru}

Berdasarkan Pedoman Pelaksanaan Penilaian Kinerja Guru (KEMENDIKBUD, 2012), mendefinisikan bahwa guru adalah pendidik profesional yang mempunyai tugas, fungsi, dan peran penting dalam mencerdaskan kehidupan bangsa. Guru yang profesional diharapkan mampu berpartisipasi dalam pembangunan nasional untuk mewujudkan insan Indonesia yang bertakwa kepada Tuhan YME, unggul dalam ilmu pengetahuan dan teknologi, memiliki jiwa estetis, etis, berbudi pekerti luhur, dan berkepribadian. Tidaklah berlebihan kalau dikatakan bahwa masa depan masyarakat, bangsa, dan negara, sebagian besar ditentukan oleh guru. Oleh sebab itu, profesi guru perlu ditingkatkan dan dikembangkan secara terus menerus dan proporsional menurut jabatan fungsional guru.

Undang-Undang No. 14 Tahun 2005 pasal 20 tentang Guru dan Dosen menyebutkan bahwa dalam melaksanakan tugas keprofesionalannya, guru berkewajiban: (a) merencanakan pembelajaran, melaksanakan proses pembelajaran yang bermutu, serta menilai dan mengevaluasi hasil pembelajaran; (b) meningkatkan dan mengembangkan kualifikasi akademis dan kompetensi secara berkelanjutan sejalan dengan perkembangan ilmu pengetahuan, teknologi, dan seni; (c) bertindak objektif dan tidak diskriminatif atas dasar pertimbangan jenis kelamin, agama, suku, ras, dan kondisi fisik tertentu, atau latar belakang keluarga, dan status sosial ekonomi peserta didik dalam pembelajaran; (d) menjunjung tinggi peraturan perundang-undangan, hukum, dan kode etik guru, serta nilai-nilai agama dan etika; dan (e) memelihara dan memupuk persatuan dan kesatuan bangsa.

\section{Hasil Penelitian Dan Pembahasan}

\section{A. Gambaran Umum Objek}

Sekolah Menengah Pertama Negeri 43 Bandung, adalah sekolah yang mengalami alih fungsi dari Sekolah Kejuruan dan Keterampilan Pertama Negeri 1 Bandung berdasarkan Surat Keputusan yang dikeluarkan Kementrian Pendidikan dan Kebudayaan Nomor 0259/O/1994 tentang Alih Fungsi Sekolah Kejuruan Pertama menjadi Sekolah Menengah Pertama.

Drs. Rahman Haryadi adalah Kepala Sekolah Menengah Pertama Negeri 43 Bandung. Berselang satu tahun, kepemimpinan Sekolah Menengah Pertama Negeri 43 Bandung digantikan oleh Maman Sutriaman, BA. Hingga saat ini, Sekolah Menengah Pertama Negeri 43 Bandung sudah mengalami enam kali pergantian kepemimpinan dan sekarang dipimpin oleh Drs. H. Endang Rochman sebagai Kepala Sekolah Menengah Pertama Negeri 43 Bandung dari tahun pelajaran 2012/2013 s.d. sekarang.

\section{B. Karakteristik Responden}

Berdasarkan hasil pengumpulan data melalui penyebaran kuesioner kepada 38 guru Pegawai Negeri Sipil yang dijadikan sebagai responden, maka dapat diketahui sebagian besar responden mengharapkan agar informasi ini dapat dijadikan sebagai masukan bagi Sekolah Menengah Pertama Negeri 43 Bandung 
dalam menyusun strategi pembinaan yang sesuai bagi seluruh pegawai/guru di masa yang akan datang untuk mencapai tujuan yang lebih baik.

Karakteristik responden yang dapat disajikan dalam penelitian ini meliputi: jenis kelamin guru, usia guru, pangkat/golongan, pendidikan formal, dan lama bekerja sebagai guru.

Karakteristik berdasarkan Jenis Kelamin

\begin{tabular}{|l|l|l|}
\hline Jenis Kelamin & Frekuensi (Orang) & Persentase (\%) \\
\hline Laki-laki & 8 & 21,05 \\
\hline Perempuan & 30 & 78,95 \\
\hline Jumlah & 38 & 100 \\
\hline
\end{tabular}

Karakteristik berdasarkan Usia

\begin{tabular}{|l|l|l|}
\hline Usia & Frekuensi (Orang) & Persentase (\%) \\
\hline $41-45$ tahun & 7 & 18,42 \\
\hline $46-50$ tahun & 21 & 55,26 \\
\hline $50-55$ tahun & 8 & 21,05 \\
\hline$>56$ tahun & 2 & 5,26 \\
\hline Jumlah & 38 & 100 \\
\hline
\end{tabular}

Karakteristik berdasarkan Pangkat/Golongan

\begin{tabular}{|l|l|l|}
\hline Pangkat/Golongan & Frekuensi (Orang) & Persentase (\%) \\
\hline III/d & 1 & 2,63 \\
\hline III/b & 2 & 5,26 \\
\hline IV/b & 3 & 7,89 \\
\hline IV/a & 32 & 84,21 \\
\hline Jumlah & 38 & 100 \\
\hline
\end{tabular}

Karakteristik berdasarkan Pendidikan Formal

\begin{tabular}{|l|l|l|}
\hline Pendidikan & Frekuensi (Orang) & Persentase (\%) \\
\hline Diploma III (D3) & 1 & 2,63 \\
\hline Strata I (S1) & 33 & 86,84 \\
\hline Strata II (S2) & 4 & 10,53 \\
\hline Jumlah & 38 & 100 \\
\hline
\end{tabular}

\section{Pengaruh Pemanfaatan Teknologi Informasi terhadap Kinerja Guru di SMP Negeri 43 Bandung}

Untuk mengungkap pengaruh sebuah variabel atau seperangkat variabel terhadap variabel lain, dapat digunakan Product Moment Pearson Correlation. Koefisien korelasi adalah suatu alat statistik, yang dapat digunakan untuk membandingkan hasil pengukuran dua variabel yang berbeda agar dapat menentukan tingkat hubungan antara variabel-variabel ini. Dalam beberapa hal, riset korelasi memang sama dengan riset komparasi sebab-akibat (causal comparative study), dan kenyataannyakoefisien korelasi biasanya dapat dihitung dari kemanfaatan menjelaskan studi komparasi sebab-akibat. (Sumarsimi Arikunti, 2010:313). 
Adapun langkah-langkah yang dilakukan adalah menghitung korelasi antar variabel, sehingga diperoleh tabel seperti di bawah ini.

Matriks Korelasi Antar Variabel

\begin{tabular}{|ll|l|l|}
\hline & & $\begin{array}{l}\text { PEMANFAATA } \\
\text { N TEKNOLOGI } \\
\text { INFORMASI }\end{array}$ & KINERJA \\
& & GURU \\
\hline PEMANFAATAN & Pearson Correlation & 1 &, $533^{* * *}$ \\
TEKNOLOGI & Sig. (2-tailed) & &, 001 \\
INFORMASI & $\mathrm{N}$ & 38 & 38 \\
& Pearson Correlation &, $533^{* *}$ & 1 \\
KINERJA GURU & Sig. (2-tailed) &, 001 & 38 \\
& $\mathrm{~N}$ & 38 & \\
\hline
\end{tabular}

Sumber: Output SPSS

Terdapat korelasi sebesar 0,533 antara variabel Pemanfaatan Teknologi Informasi (X) dan variabel Kinerja Guru (Y). Apakah kaoefisien korelasi tersebut signifikan atau tidak maka perlu dibandingkan dengan $\mathrm{r}$ tabel, dengan taraf kesalahan tertentu. Bila taraf kesalahan ditetapkan 5\% (taraf kepercayaan 95\%) dan $n=38$, maka harga $r$ tabel $=0,361$. Ternyata harga $r$ hitung lebih besar daripada $r$ tabel, sehingga Ho ditolak dan Ha diterima. Jadi kesimpulannya ada hubungan positif dan nilai korelasi antara Pemanfaatan Teknologi Informasi (X) dengan Kinerja Guru (Y).

\section{Kesimpulan dan Saran}

\section{A. Kesimpulan}

Berdasarkan hasil penelitian yang telah dilakukan untuk mengetahui pengaruh pemanfaatan teknologi informasi terhadap kinerja guru pada Sekolah Menengah Pertama Negeri 43 Bandung, maka dapat ditarik kesimpulan sebagai berikut:

1. Pemanfaatan teknologi informasi pada Sekolah Menengah Pertama Negeri 43 Bandung memiliki tingkat pemanfaatan yang baik, dalam arti para guru sudah mulai memanfaatkan teknologi informasi dalam melakukan pengajaran, seperti tugas-tugas dan materi-materi dapat diunduh melalui internet; tugas dapat dikirimkan melalui surat elektronik (e-mail). Namun ada beberapa hal yang perlu ditingkatkan seperti etika dalam penggunaan teknologi informasi; perilaku yang baik dalam menggunakan teknologi; dan keinginan atau kesadaran untuk memanfaatkan teknologi informasi.

2. Kinerja guru pada Sekolah Menengah Pertama Negeri 43 Bandung berada pada tingkat kinerja yang tinggi, namun ada beberapa hal yang perlu ditingkatkan lagi yaitu tanggung jawab terhadap jumlah kerja yang dilakukan dalam suatu periode yang telah ditentukan berdasarkan PP No. 74 Pasal 52 ayat (2), efisiensi waktu untuk mengerjakan suatu pekerjaan, gagasan atau ide yang dimunculkan, tingkat penyelesaian kerja, menyusun bahan ajar secara runtut; logis; kontekstual; dan mutakhir, merencanakan kegiatan pembelajaran yang efektif, memulih sumber belajar/media pembelajaran 
sesuai dengan materi dan strategi pembelajaran, memulai pembelajaran dengan efektif, merancang alat evaluasi untuk mengukur kemajuan dan keberhasilan peserta didik, menggunakan berbagai strategi dan metode penilaian untuk memantau kemajuan dan hasil belajar peserta didik dalam mencapai kompetensi tertentu sebagaimana yang tertulis dalam RPP.

\section{B. Saran}

Berdasarkan hasil penelitian dan pengamatan yang telah dilakukan, maka penulis ingin mengajukan beberapa saran yang dapat dijadikan pertimbangan bagi Sekolah Menengah Pertama Negeri 43 Bandung untuk meningkatkan kinerja guru.

Adapun saran-saran tersebut antara lain adalah:

1. Tingkatkan pemanfaatan teknologi informasi serta penggunaan media dalam pembelajaran, sehingga pemberian materi dalam kelas tidak membosankan. Tingkatkan etika dalam penggunaan teknologi informasi; perilaku yang baik dalam menggunakan teknologi; dan keinginan atau kesadaran untuk memanfaatkan teknologi informasi.

2. Tingkatkan kinerja guru terutama dalam hal tanggung jawab terhadap jumlah kerja yang dilakukan dalam suatu periode yang telah ditentukan berdasarkan PP No. 74 Pasal 52 ayat (2), efisiensi waktu untuk mengerjakan suatu pekerjaan, gagasan atau ide yang dimunculkan, tingkat penyelesaian kerja, menyusun bahan ajar secara runtut; logis; kontekstual; dan mutakhir, merencanakan kegiatan pembelajaran yang efektif, memulih sumber belajar/media pembelajaran sesuai dengan materi dan strategi pembelajaran, memulai pembelajaran dengan efektif, merancang alat evaluasi untuk mengukur kemajuan dan keberhasilan peserta didik, menggunakan berbagai strategi dan metode penilaian untuk memantau kemajuan dan hasil belajar peserta didik dalam mencapai kompetensi tertentu sebagaimana yang tertulis dalam RPP.

\section{Daftar Pustaka}

[1] Ali Muhtadi, 2013, Pemanfaatan Teknologi Informasi dan Komunikasi (TIK) dalam Pendidikan Karakter di Sekolah, Yogyakarta.

[2] Davis, F. D., Bagozzi, R. P., and Warshaw, P. R., 1989, "User Acceptance of Computer Technology: A Comparison of Two Theoretical Models," Management Science, 35, 982-1003.

[3] DEPDIKNAS, 2009, Pedoman Pelaksanaan Tugas Guru dan Pengawas, Jakarta

[4] Dinkominfo, 2013, Manfaat Teknologi Informasi dan Komunikasi dalam Pendidikan, Surabaya.

[5] Herman Dwi Surjono, 2010, Pemanfaatan Teknologi Informasi dan Komunikasi dalam Peningkatan Kualitas Pembelajaran, Makalah, Magelang. 
[6] Jejen Mushaf, 2011, Peningkatan Kompetensi Guru, Edisi Pertama, Cetakan ke-1, Kencana Prenada Media Group-Jakarta

[7] KEMENDIKBUD, 2012. Pedoman Pemenuhan Standar Nasional Pendidikan pada Sekolah Menengah Pertama (SEKOLAH MENENGAH PERTAMA)/Madrasah Tsanawiyah (MTS), Jakarta

[8] KEMENDIKBUD, 2012, Sertifikasi Guru dalam Jabatan Tahun 2013: Pedoman Penetapan Peserta, Jakarta

[9] Messa Media Gusti, 2012, Pengaruh Kedisiplinan, Motivasi Kerja, dan Persepsi Guru tentang Kepemimpinan Kepala Sekolah terhadap Kinerja Guru SMKN 1 Purworejo Pasca Sertifikasi, Jurnal, Yogyakarta

[10] Sumarsimi Arikunto, 2010, Prosedur Penelitian (Suatu Pendekatan Praktik), Jakarta.

[11] Suwarsih Madya, (Februari 2011), Optimalisasi Pemanfaatan TIK untuk Meningkatkan Mutu Hakiki Pendidikan, Makalah, Seminar Nasional, Milad UAD XXX.

[12] Undang-Undang Republik Indonesia Nomor 14 Tahun 2005 tentang Guru dan Dosen, Jakarta.

[13] Wibowo, 2013, Manajemen Kinerja, PT, Raja Grafindo Persada, Kelapa Gading, Jakarta.

[14] Wirawan, 2009, Evaluasi Kinerja Sumber Daya Manusia, Erlangga, Jakarta.

[15] Yusufhadi Miarso, 2004, Menyemai Benih Teknologi Pendidikan, JakartaKencana. 